\title{
Application of Monte Carlo Simulation Method to Tensile Behavior of FRM
}

\author{
Shojiro Ochiai, Takehiro Sawada and Masaki Hojo \\ Mesoscopic Materials Research Center, Faculty of Engineering, \\ Kyoto University, Sakyo-ku, Kyoto 606-01, Japan
}

\begin{abstract}
The Monte Carlo simulation method was applied to describe the tensile behavior of unidirectional singleand multi-fiber-metal matrix composites. The simulation for single fiber-composites could describe the experimental results of the progress of multiple fracture of fiber with increasing applied stress and the influence of fiber volume fraction on the final average length of broken fiber in the $\mathrm{W}$ (fiber)/Cu(matrix). By applying this method to the multiple fracture process, the interfacial shear strengths of the high $\mathrm{T}_{c}$ oxides $\left(\mathrm{YBa}_{2} \mathrm{Cu}_{3} \mathrm{O}_{\mathrm{x}}\right.$ and $\left.\mathrm{Ba}_{2} \mathrm{Sr}_{3} \mathrm{Ca}_{2} \mathrm{Cu}_{3} \mathrm{O}_{\mathrm{y}}\right) / \mathrm{Ag}$ were estimated to be nearly 30 and $40 \mathrm{MPa}$, respectively. The simulation for multi-fiber composites could describe well the experimentally observed results such as the relation of scatter of strength of the contained fibers to the fracture mode of $\mathrm{B} / \mathrm{Al}$, influences of scatter of strength of fibers on the scatter of strength of $\mathrm{Nb}_{3} \mathrm{Al} / \mathrm{Cu}$ composite, the gauge-length-dependence of strength of $\mathrm{Nb}_{3} \mathrm{Al} / \mathrm{Cu}$ composite, temperature-dependence of the strength of Si-Ti-C-O (Tyrrano fiber)/Al composite, and influence of fabrication condition on the fracture morphology and strength of B/Al.
\end{abstract}

\section{KEY WORDS:}

Monte Carlo simulation, strength, fracture, fiberreinforced metal, shear lag analysis, Weibull distribution.

\section{INTRODUCTION}

In single fiber-metal matrix composites, the initially continuous fiber contained shows multiple fracture before the fracture of composites, when the volume fraction of the fiber is lower than a critical value. This phenomenon occurs through the following process $/ 1$. The breakage of a fiber in one cross-section causes a drop in the load bearing capacity of the composites. In this cross-section, however, the matrix work hardens and the load bearing capacity of this cross-section rises again so that the fiber, once broken, fails in another cross-section. As this process is repeated, the breakage of the fiber is accumulated. The accumulation process is different from sample to sample, since the strength distribution along the length of the fiber (or the distribution of size and locations of defects in the fiber) is different among samples.

In the case of unidirectional multi-fiber metal matrix composites, various events such as breakage, pull-out and bridging of fibers, interfacial debonding and so on occur. These events, occurring at different locations, are accumulated with increasing applied stress, and co-operate to cause overall fracture of composites. The number and location of these events are dependent on the applied stress and they also differ from sample to sample, resulting in scatter of fracture process and strength of composites $/ 2 /$.

In light of the above, a method is needed to describe the accumulation process of the events, their total contribution to the overall fracture of composites and the scatter of strength of composites. The Monte Carlo simulation method is one which may well satisfy that need. The authors have been developing this method, and have been able to describe successfully some experimental results on the fracture process and strength of unidirectional single- and multi-fiber composites. In the present paper, the results of applying this method to the multiple fracture phenomenon of fiber in 
single fiber-metal matrix composites (W(fiber)/ $\mathrm{Cu}$ (matrix)) and high $\mathrm{T}_{\mathrm{c}}$ superconducting oxide composite $\left(\mathrm{YBa}_{2} \mathrm{Cu}_{3} \mathrm{O}_{\mathrm{x}} / \mathrm{Ag}\right.$ and $\left.\mathrm{Bi}_{2} \mathrm{Sr}_{2} \mathrm{Ca}_{2} \mathrm{Cu}_{3} \mathrm{O}_{\mathrm{y}} / \mathrm{Ag}\right)$, and tensile behavior and strength of unidirectional multifiber ones (B/Al, Si-Ti-C-O (Tyrrano fiber)/Al, $\left.\mathrm{Nb}_{3} \mathrm{Al} / \mathrm{Cu}\right)$ ), are summarized.

\section{THE SIMULATION PROCEDURE}

The simulation procedure is briefly summarized as follows. The details for particular situations are shown elsewhere /3-10/.

A. Multiple fracture of fiber in single-fiber composite /3-6/

1) The fiber was considered to be composed of a number of short elements $N$ with a length $L_{e}$, and the elements were numbered from 1 to $\mathrm{N}$, as shown in Fig. 1(a).

2) For each element, the strength was given by generating a random value. The Weibull distri-

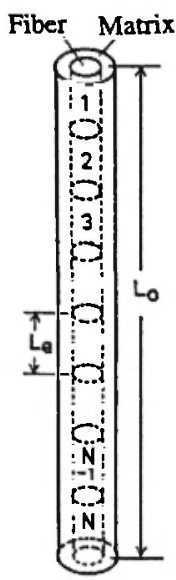

(a)

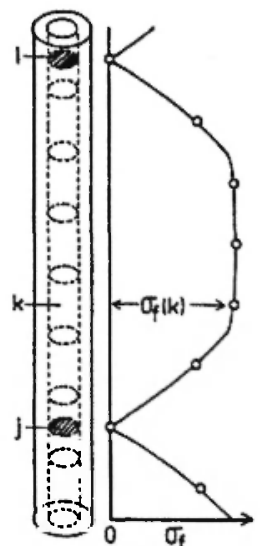

(b)

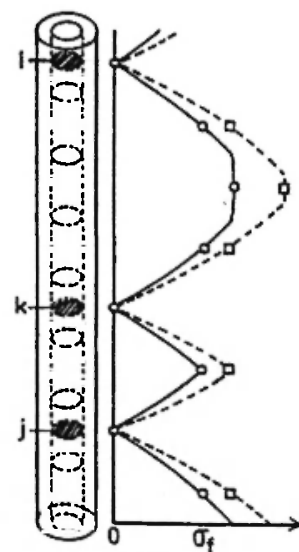

(c)
Fig. 1: Schematic representation of (a) the numbering of elements for the Monte Carlo simulation, (b) stress distribution in the fiber in the case where the $i$ and $j$ elements have been broken, and (c) stress re-distribution in the fiber due to the fracture of the $\mathrm{k}$ element (solid curve), which changes to that shown by the broken curve when the applied stress is raised $/ 6 /$. bution function /11/ was used to give the distribution of fiber strength, since this function has been known to describe well the distribution of strength of materials; this also provides a mathematically convenient expression for the length-dependence of the distribution.

3) When stress is applied on a composite, the elements with low strengths are broken when the stresses exerted on those elements exceed their strengths. When the $i$ and $j$ elements are broken, the stress distribution in the fiber is calculated by the method presented in Ref. 15/ for strong interface and in Ref. /6/ for weak interface, and the stress at the midpoint of each element was regarded as the representative exerted stress for each element, as shown in Fig. 1(b). When the exerted stress was higher than the strength of the $\mathrm{k}$ element, the $\mathrm{k}$ element was judged to be broken. The stress redistribution due to the fracture of the $k$ element was subsequently calculated as shown by a solid curve in Fig. 1(c).

4) With increasing applied stress, the exerted stress on each element varies as shown by the broken curve in Fig. 1(c). Under the increased applied stress, whether any elements be broken or not was examined in a similar manner.

5) For each stress level, steps 3) and 4) mentioned above were repeated until the failure of the composite. The failure of the composite was judged to occur when the exerted stress on the matrix in the cross-section, in which the fiber is broken, exceeds the ultimate strength of the matrix.

\section{B. Multi-fiber composite $/ 7-10 /$.}

When stress is applied to a composite, fiber breakages occur, as shown in Fig. 2(a). As a result, the stress carrying capacity of broken fibers is lost within half critical length $\left(l_{0} / 2\right)$ from the broken end (Fig. 2(b)) and stress is concentrated in the neighboring fibers (Fig. 2(c), where $\sigma_{f}$ is the stress of fiber at infinity apart from the broken end and $\mathrm{K}$ is the stress concentration factor). For calculation of such stress-disturbances, the shear lag analysis method /13-15/ was used, which assumes that only fibers carry applied stress and matrix plays a role only as a stress-transfer medium. This assumption has been demonstrated to be valid when the volume 


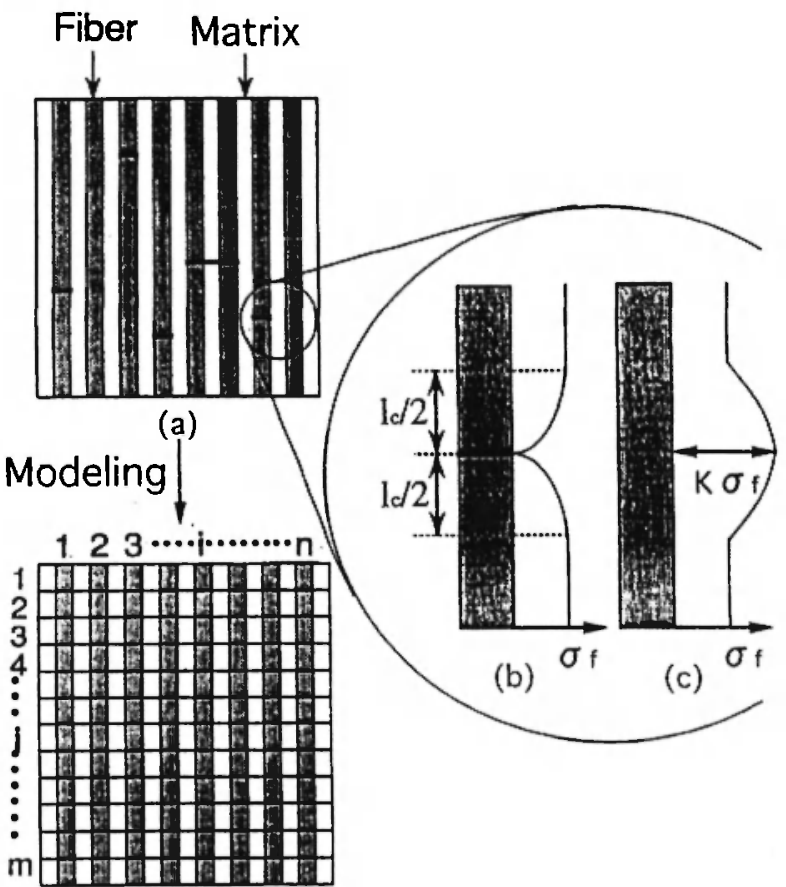

(d)

Fig. 2: Schematic representation of (a) breakages of fibers in the composite, (b) loss of stress carrying capacity of broken fiber, (c) stress concentration in the neighboring fiber and (d) modelling of multi-fiber composites for the Monte Carlo simulation /12/.

fraction of fiber is high and stress of the matrix is low in comparison with that of fibers $116,17 /$. For this reason, the application of the present method is limited to the composites satisfying such conditions.

1) A two-dimensional model was used. Each fiber was regarded as being composed of many short elements and the composite composed of such fibers is shown in Fig. 2(d).

2) The strength of each element was given by generating a random value, similar to that for single fiber composites.

3) The exerted stress was calculated by the shear lag analysis modified for metal matrix composites /1315\%. When the exerted stress was higher than the strength for each element, the element was considered to be broken.

4) The occurrence of overall fracture of the composite was judged in the following manner. Fracture of composite is caused either by a chain reaction of the breakage of fibers due to stress concentration in one cross-section or by pull-out of the fibers. The pullout of fibers was judged to occur if the longitudinal distance between the broken ends of neighboring fibers is smaller than the critical length, since broken fibers can be pulled out when the broken ends exists within half the critical length from the fracture surface. In the fracture process accompanying the pull-out of fibers, the final fracture of the composite was judged to occur when all fibers are broken and the broken end of each fiber exists within a critical length from that of neighboring fibers one after another in transverse direction.

\section{RESULTS}

\subsection{Multiple fracture of fiber in single fiber composite}

\subsubsection{Multiple fracture of fiber in the composite with strong interface:}

Single W(fiber with a diameter $100 \mu \mathrm{m}$ ) $/ \mathrm{Cu}$ (matrix) composite specimens whose interface is strong was used in this study $/ 3 /$.This composite has an interfacial shear strength of $94 \mathrm{MPa}$ measured by the pull-out test, which is more than twice as high as the shear yield stress of the copper matrix, $41 \mathrm{MPa}$. From the Weibull plot, the measured strength distribution of the bare fiber, the shape (m) and scale $\left(\sigma_{0}\right)$ parameters in the two-parameter Weibull distribution function were determined to be 10.1 and $1.31 \mathrm{GPa}$ (in the expression for a standard length $1 \mathrm{~mm}$ ), respectively. For the simulation, the values mentioned above, together with other parameters such as Young's and shear moduli of the fiber and matrix, gauge length $(30 \mathrm{~mm}$ in this case, the same as in the experiment), tensile and shear yield stresses and strain hardening coefficient of the matrix, etc., were input.

Figure 3 shows some typical load-elongation curves and the appearance of the fiber after multiple fracture in the composite with the volume fraction of fiber $V_{f}=$ 0.01 . The sudden drops in the curves correspond to the 


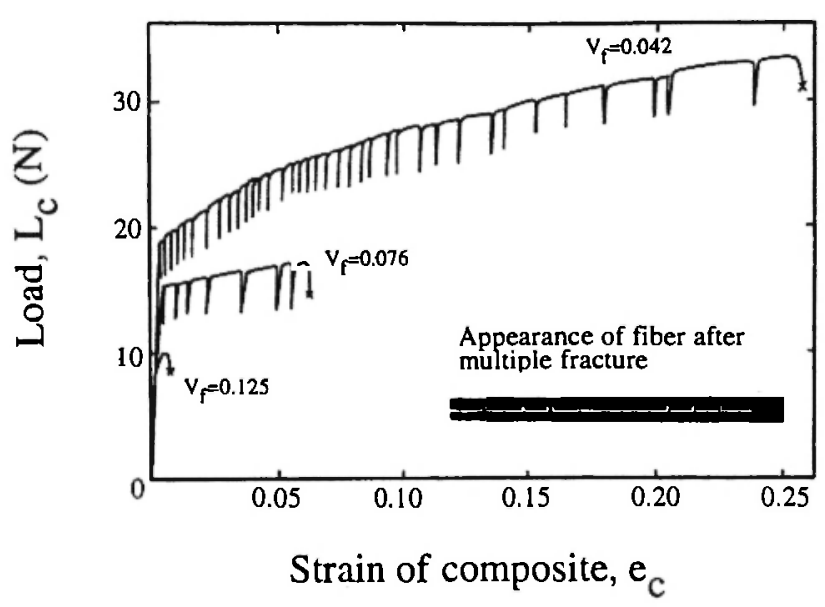

Fig. 3: Typical load-elongation curves of W/Cu single fiber-composite, together with the appearance of fiber after multiple fracture $13 /$.

fracture of the fiber. The fracture of the fiber occurred continually with increasing stress level when $V_{f}$ was lower than 0.1 .

The number of fractures of the fiber was estimated by counting the number of drops in the load-elongation curves. Figure 4 shows the dependence of the number of fractures at the fracture of composite, $N_{\mathfrak{f}}$ on $V_{f} / 3$. This result indicates that the critical length depends on

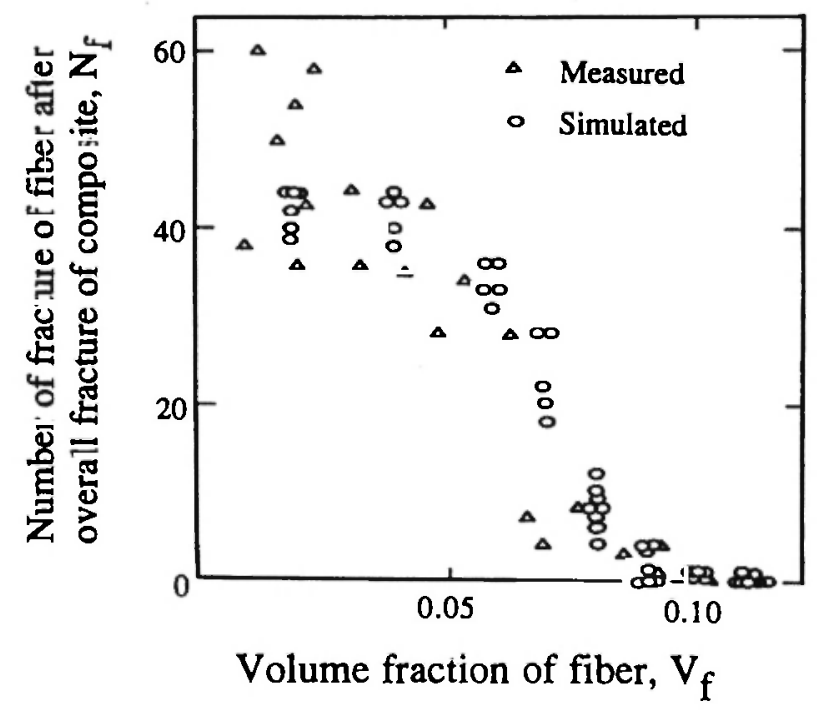

Fig. 4: Measured and simulated number of fracture $\mathrm{N}_{\mathrm{f}}$ of the $\mathrm{W}$ fiber at the fracture of $\mathrm{W} / \mathrm{Cu}$ single fiber-composite, plotted against volume fraction of fiber, $\mathrm{V}_{\mathrm{f}} / 3$ \%
$V_{f}$. Also the strain to failure of the composite $e_{\mathrm{cu}}$ decreased with increasing $V_{f}$ as shown in Fig. $5 / 3 /$. The experimentally measured results $(\Delta)$ shown in Figs. 4 and 5 were fairly well described by the simulation (0).



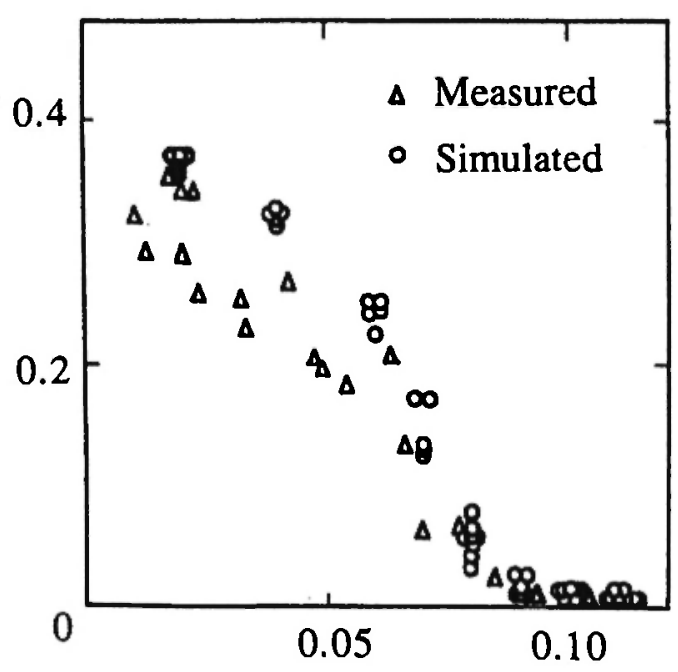

\section{Volume fraction of fiber, $\mathrm{V}_{\mathrm{f}}$}

Fig. 5: Measured and simulated elongation to failure $e_{c u}$ of $W / C u$ single fiber-composite, plotted against volume fraction of fiber, $V_{f} / 3 /$.

Figure 6 shows some representative results of the simulation on the process of multiple fracture of the fiber. It is clearly shown that the fiber is broken into more and more segments with increasing stress level for both cases $V_{f}=0.04$ and 0.08 , but the number of fractures of the fiber for $V_{f}=0.08$ is smaller than for $V_{f}$ $=0.04$. The feature found in the experiment, that the fibers embedded in the composite with lower $V_{f}$ can be broken into shorter segments, is well simulated.

As the number of fractures of the fiber is dependent on the initial length of the specimen, it is more convenient to compare the critical aspect ratio $\left(l_{d} / d_{f}\right)$ of the broken fibers obtained by the experiment with that obtained by the simulation (Fig. $7 / 3 /$ ). $1 / d_{\mathrm{f}}$ increases gradually for about $V_{f}<0.06$ but rapidly for $V_{f}>0.06$ with increasing $V_{f}$ and it approaches infinity beyond about $V_{f}=0.1$. In this single fiber composite, $V_{f}=0.1$ 


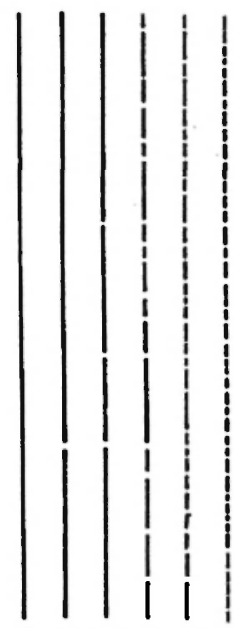

123456

(a) Volume fraction of fiber $V_{f}=0.04$

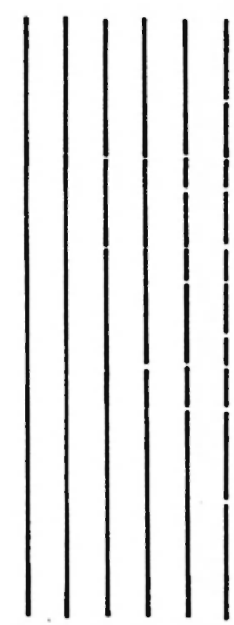

123456

(b) $\mathrm{V}_{\mathrm{f}}=0.08$
Fig. 6: Examples of the simulated multiple fracture of the $W$ fiber in $W / C u$ single fibercomposite with $V_{f}=$ (a) 0.04 and (b) 0.08 . In (a), the numbers 1 to 6 correspond to the stress levels of $\sigma_{c}=120,125,130,135,150$ $\mathrm{MPa}$ and at fracture of composite, and in (b), they correspond to $\sigma_{\mathrm{o}}=150,160,170,175$, $180 \mathrm{MPa}$ and at fracture of composite, respectively.

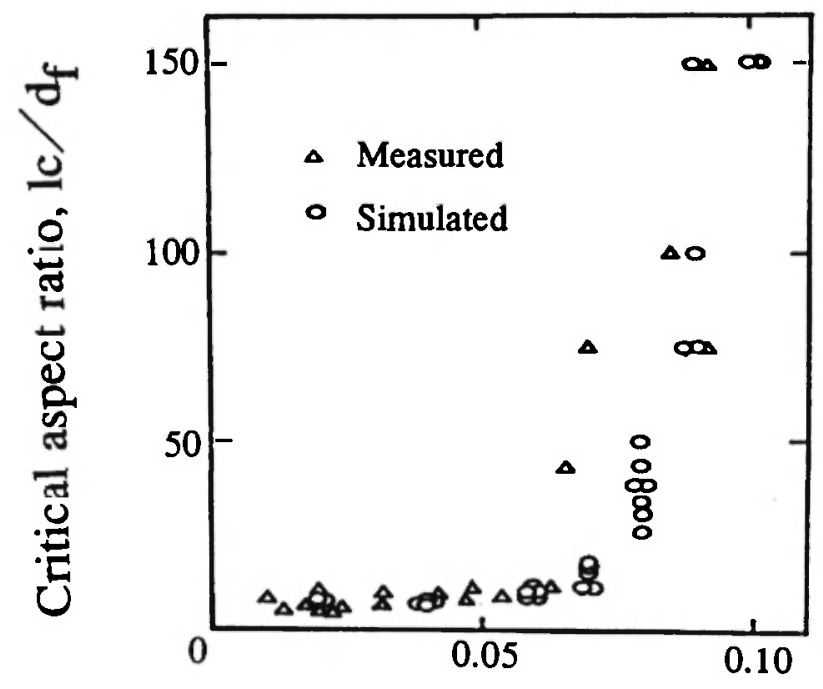

\section{Volume fraction of fiber, $\mathrm{V}_{\mathrm{f}}$}

Fig. 7: Comparison of the measured and simulated values of the critical aspect ratio $1_{d} / d_{f}$ of the W fiber at the fracture of $\mathrm{W} / \mathrm{Cu}$ composite /3/. is the critical volume fraction for multiple fracture to occur. This means that $l_{o} / d_{f}$ becomes infinite (or gauge length in practice) at this critical $V_{f}$. In other words, the critical $V_{f}$ for multiple fracture of fiber to occur may be defined as the $V_{f}$ at which critical aspect ratio becomes infinite (or gauge length) in single fiber composites. It should be noted that the $l_{d} / d_{r}$-value is dependent on $V_{f}$ in the case of single fiber composites.

\subsubsection{Multiple fracture of fiber in the composite with weak interface.}

$\mathrm{Bi}_{2} \mathrm{Sr}_{2} \mathrm{Ca}_{2} \mathrm{Cu}_{3} \mathrm{O}_{\mathrm{y}}$ and $\mathrm{YBa}_{2} \mathrm{Cu}_{3} \mathrm{O}_{\mathrm{x}}$ are known as high $\mathrm{T}_{\mathrm{o}}$ oxide superconductors. For practical use, these oxides are embedded in silver in the form of fiber. Figure 8 shows typical stress-strain curves of $\mathrm{Bi}_{2} \mathrm{Sr}_{2} \mathrm{Ca}_{2} \mathrm{Cu}_{3} \mathrm{O}_{\mathrm{y}} /$

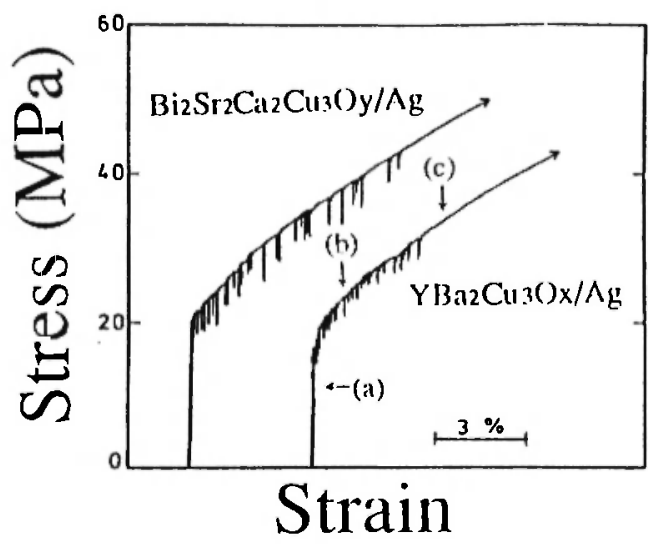

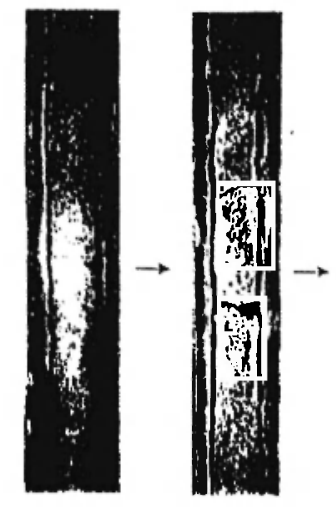

(a) (b)

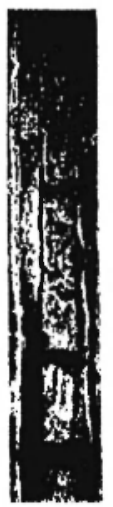

(c)
Fig. 8: Typical stress-strain curves of the superconducting high $T_{0}$ oxide composites, $\mathrm{YBa}_{2} \mathrm{Cu}_{3} \mathrm{O}_{\mathrm{x}} / \mathrm{Ag}$ and $\mathrm{Bi}_{2} \mathrm{Sr}_{2} \mathrm{Ca}_{2} \mathrm{Cu}_{3} \mathrm{O}_{\mathrm{y}} / \mathrm{Ag}$, together with the appearance of the $\mathrm{YBa}_{2} \mathrm{Cu}_{3} \mathrm{O}_{\mathbf{x}}$ before and after multiple fracture. 
$\mathrm{Ag}$ and $\mathrm{YBa}_{2} \mathrm{Cu}_{3} \mathrm{O}_{\mathrm{x}} / \mathrm{Ag}$ composites, together with the appearance of the oxide before and after multiple fracture of the $\mathrm{YBa}_{2} \mathrm{Cu}_{3} \mathrm{O}_{\mathrm{x}} / 6 /$. The drops in the curves correspond to the fracture of the oxide, similar to those for W/Cu composites (Fig. 3). The number of fractures, $\mathbf{N}_{\hat{f}}$, of the oxides increased with increasing applied stress, $\sigma_{c}$, on composites up to nearly 43 and $32 \mathrm{MPa}$ for $\mathrm{Bi}_{2} \mathrm{Sr}_{2} \mathrm{Ca}_{2} \mathrm{Cu}_{3} \mathrm{O}_{y} / \mathrm{Ag}$ and $\mathrm{YBa}_{2} \mathrm{Cu}_{3} \mathrm{O}_{\mathrm{x}} / \mathrm{Ag}$ composites, respectively. However, no more fractures were observed above these stress levels. The reason why further fracture of the oxide was suppressed at high applied stress could be attributed to the interfacial debonding from the observation of fracture surface $/ 6 /$. In order, therefore, to estimate the interfacial shear strength, the Monte Carlo simulation was applied, followed by the estimation of Weibull parameters from the relation of the number of breakages to the exerted stress on the oxides in the early stages of multiple fracture $(\mathrm{m}=4.7$ and $\sigma_{0}$ (in the expression for a standard length $1 \mathrm{~mm}$ ) = $108 \mathrm{MPa}$ for $\mathrm{Bi}_{2} \mathrm{Sr}_{2} \mathrm{Ca}_{2} \mathrm{Cu}_{3} \mathrm{O}_{y}$ and $\mathrm{m}=3.5$ and $\sigma_{0}=118$ $\mathrm{MPa}$ for $\mathrm{YBa}_{2} \mathrm{Cu}_{3} \mathrm{O}_{\mathrm{x}} / 6 /$ ).

The simulation experiment was carried out for various assumed values of shear strength of interface $\left(\tau_{i}\right)$. The results of five simulations for $\tau_{1}=30,40$ and $50 \mathrm{MPa}$ for $\mathrm{Bi}_{2} \mathrm{Sr}_{2} \mathrm{Ca}_{2} \mathrm{Cu}_{3} \mathrm{O}_{y} / \mathrm{Ag}$ are presented in Fig. 9 $16 /$. The hatched and dotted regions show the measured and simulated results, respectively. When the $\tau_{\mathrm{i}}$ value was taken to be $40 \mathrm{MPa}$, the experimental result could be described fairly well. This means that the shear strength of interface between $\mathrm{Bi}_{2} \mathrm{Sr}_{2} \mathrm{Ca}_{2} \mathrm{Cu}_{3} \mathrm{O}_{\mathrm{y}}$ and silver was nearly $40 \mathrm{MPa}$. In a similar manner, the shear strength of $\mathrm{YBa}_{2} \mathrm{Cu}_{3} \mathrm{O}_{\mathrm{x}} / \mathrm{Ag}$ was estimated to be nearly $30 \mathrm{MPa}$. In this way, from the comparison of the simulation results with experimental ones on multiple fractures of fiber, the shear strength of interface could be estimated.

\subsection{Multi-fíber composite}

\subsubsection{Influence of scatter of fiber strength on fracture mode of composite.}

Herring et al. $/ 18 /$ examined experimentally the influence of scatter of fiber strength on the fracture and strength of mono- and bi-layer $\mathrm{B} / \mathrm{Al}$ composites. They found that, when the scatter of the fiber strength (white histogram) is small, the breakages of a few weaker

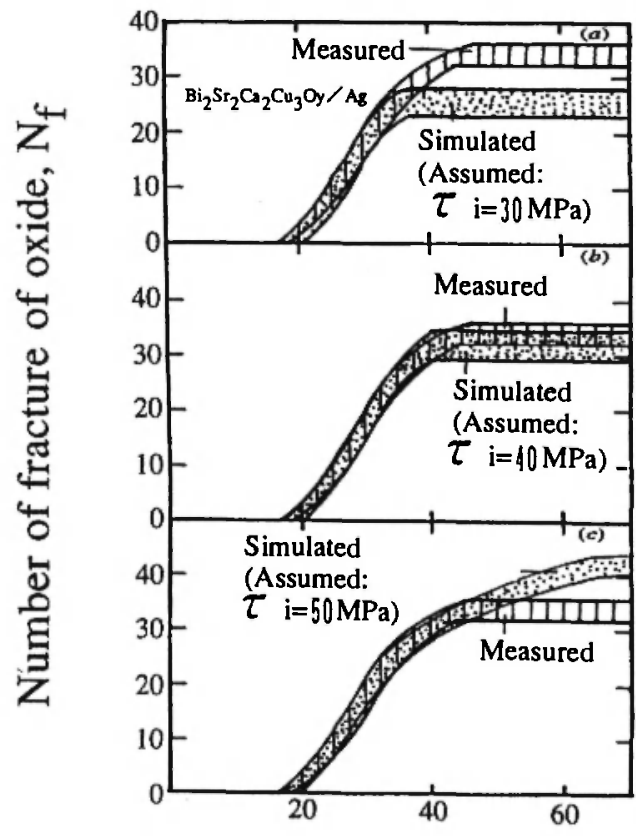

Applied Stress on Composite, $\sigma \mathrm{c}(\mathrm{MPa})$

Fig. 9: Comparison of the simulation results on the number of fracture of $\mathrm{Bi}_{2} \mathrm{Sr}_{2} \mathrm{Ca}_{2} \mathrm{Cu}_{3} \mathrm{O}_{\mathrm{y}}$ fiber, $N_{f}$, as a function of $\sigma_{c}$, for $\tau_{i}=$ (a) 30 , (b) 40 and (c) $50 \mathrm{MPa}$ with the experimental results. The dotted and hatched regions show the scatter for five simulated and measured samples, respectively $/ 6 /$.

fibers (hatched ranges) causes the overall fracture of the composite (non-cumulative mode (Fig. 10(a)), but when the scatter is large, the composite fails after accumulation of the breakages of weaker fibers (cumulative fracture mode (Fig. 11(a)).

In order to examine whether such experimental results can be realized in the computer or not, the scatter of fiber stress at composite fracture (hatched range) was simulated using the distribution of the strength of the fibers (white histogram) in Figs. 10(a) and 11(a). The results of 100 times simulation are shown in Figs. 10(b) and 11(b) for small and large scatters of fiber strength, respectively. In addition, the average stress of fiber versus strain-curves and the occurrence of fiber-breakages during tensile test were also simulated. Examples of the simulation results for small and large scatters of fiber strength are shown in Figs. 10(c) and 11(c), respectively, where the snapshots 

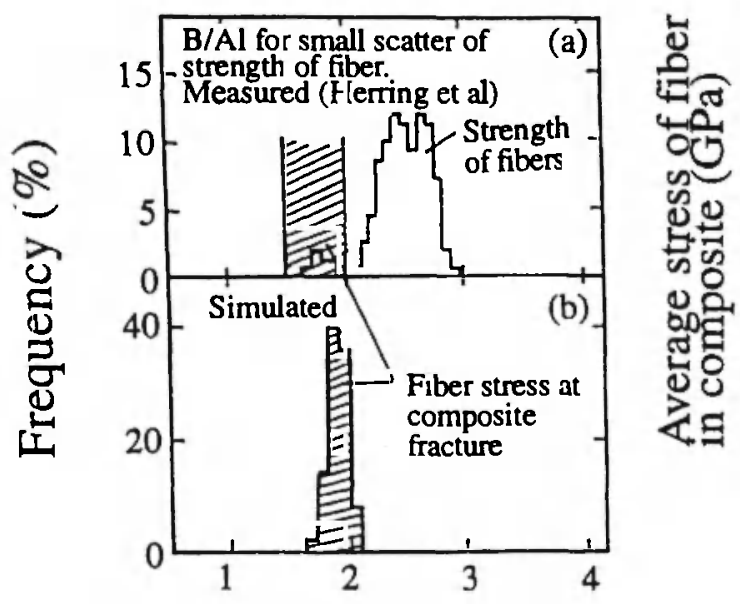

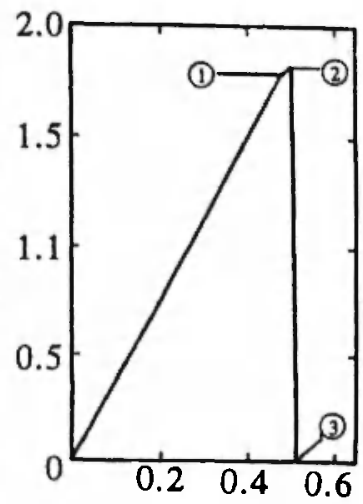

Strain (\%) (c)

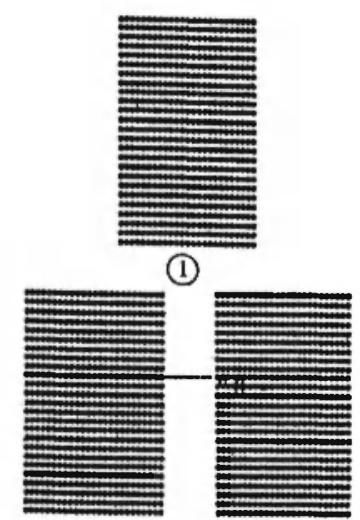

(2)

(3)

\section{Stress (GPa)}

Fig. 10: (a) Measured distribution of strength of fiber and fiber stress at fracture of B/Al composite for small scatter of fiber strength $/ 18 /$, (b) simulated fiber stress at fracture of composite, and (c) simulated average fiber stress-strain curve and snap-shots at the stress levels indicated. $O$ and * in (c) show unbroken and broken elements, respectively.

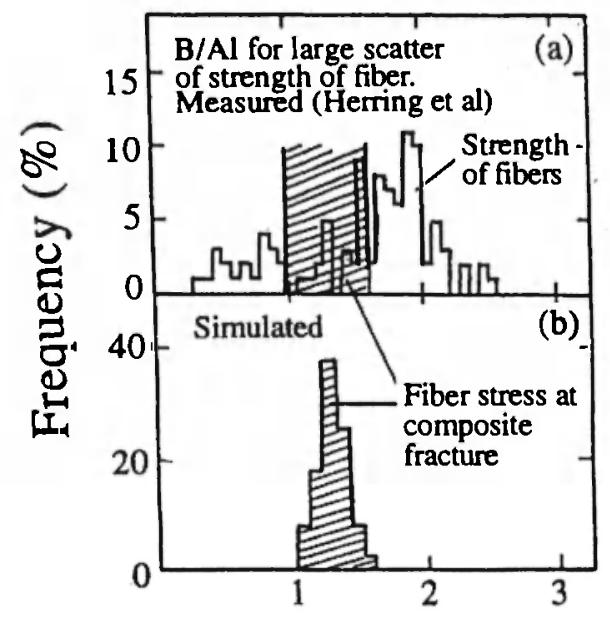

Stress (GPa)
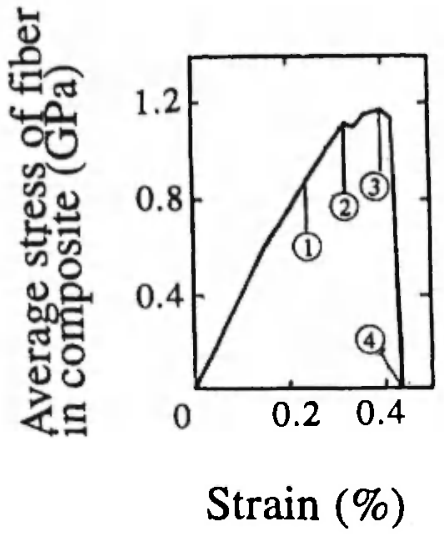

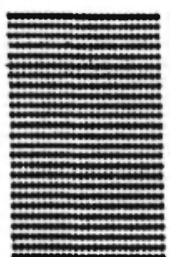

(1)

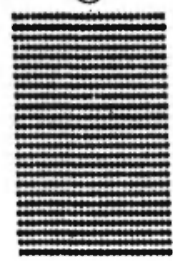

(3)

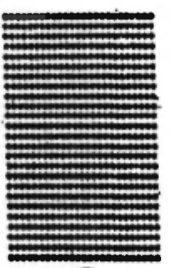

(2)

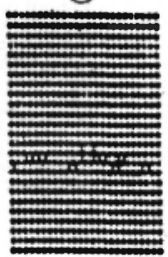

(4)

(c) 
strength on the fracture mode, the experimentally observed feature was also well described by the simulation as follows. In the case of small scatter, the simulated number of breakages of fiber was very small. In the example shown in Fig. 10(c), no fiber breakage had occurred in the final fracture surface just before the overall fracture of the composite, indicating that one breakage of the fiber in the final fracture surface caused breakages of the neighboring fibers one after another, resulting in non-cumulative fracture of composite. On the other hand, in the case of large scatter, the breakages of the weaker fiber-elements shown by * in Fig. 11(c) are accumulated with increasing applied stress, which characterizes well the cumulative fracture mode.

\subsubsection{Relation of strength distribution of fiber to that of composite.}

When the strength distribution of fibers (white histogram) is compared to the range of fiber stresses at fracture of composite (hatched range) in Figs. 10 and 11 , there was found to be a tendency for the latter to be smaller than the former. This indicates that the scatter of strength in composites is smaller than that in fibers; namely, the reliability of composites is high in spite of the large scatter of strength of the stress-carrying fibers. This feature also leads to the speculation that the length-dependence of composite strength is smaller than that of fiber strength since, as the long composites are composed of short ones, the small scatter in strength of short composites results in small scatter in strength of long ones.

The indications and speculations mentioned above were examined by experiment and simulation using the $\mathrm{Nb}_{3} \mathrm{Al} / \mathrm{Cu}$ superconducting composite wires $/ 12 /$. Experimentally, (i) the strength distribution of the composite for a fixed gauge length $\mathrm{L}_{0}=50 \mathrm{~mm}$ was measured by testing 60 samples, (ii) the length dependence of average strength of composite was measured for the gauge lengths from 20 to $350 \mathrm{~mm}$ by testing 10 samples for each gauge length, (iii) the strength distribution of extracted $\mathrm{Nb}_{3} \mathrm{Al}$ fibers was measured for the gauge lengths of 20,50 and $150 \mathrm{~mm}$ by testing more than $\mathbf{4 0}$ samples for each gauge length. From the results of (iii), the shape and scale parameters for the fiber strength were estimated at $\mathbf{7 . 0}$ and $\mathbf{5 3 0}$
MPa (in the expression for a standard length $1 \mathrm{~m}$ ), respectively. Using parameters determined in this way, the strength distribution of composite for $\mathrm{L}_{0}=50 \mathrm{~mm}$ and dependence of average strength of composite on gauge length $\left(L_{0}=20,50,150\right.$ and $\left.350 \mathrm{~mm}\right)$ were simulated 100 times and 10 times for each gauge length, respectively. The simulation results thus obtained were compared with the experimental ones.

The measured relation of scatter of fiber strength to scatter of composite strength for a fixed gauge length $\mathrm{L}_{0}=50 \mathrm{~mm}$ and the measured length-dependence of average strengths of fiber and composite for $L_{0}=20$ to $350 \mathrm{~mm}$ are presented in Figs. 12 and 13, respectively. The measured coefficient of variation of strength of composite was only $0.8 \%$ although that of fibers was too high (16\%) for a fixed length (Fig. 12). Also the average strength of composite remained nearly constant while that of fibers decreased markedly with increasing length (Fig. 13). The results of simulation are superimposed in Figs. 12 and 13. Both the simulated strength distribution of composite for a given length (Fig. 12) and length-dependence of average strength of the composite (Fig. 13) are in fairly good agreement with the experimental values.

In general, the scatter of strength of the composite arises from the following causes $/ 19,20 \%$. When fiber strength scatter is small, a non-cumulative fracture mode controls the strength. In this case, the scatter of

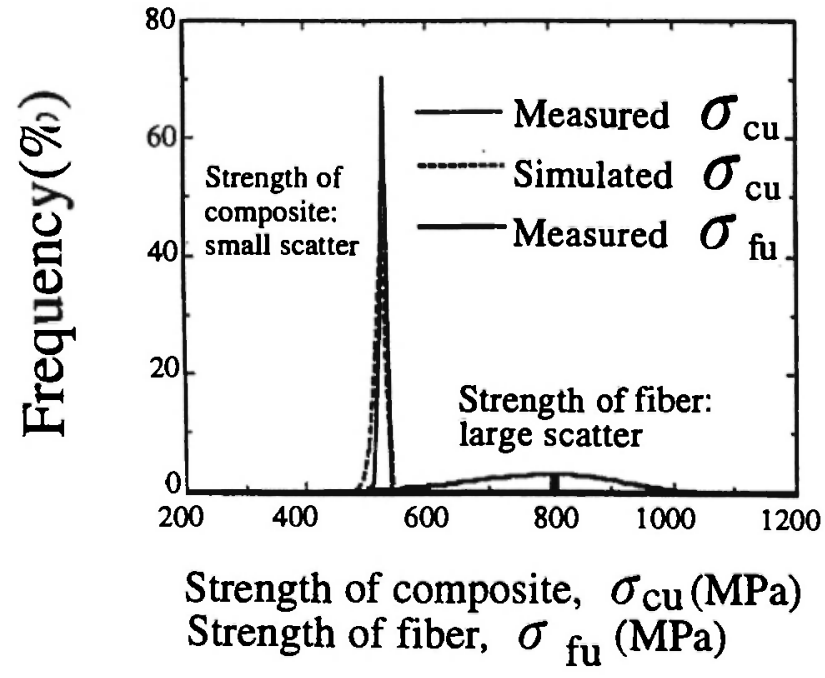

Fig. 12: Comparison of distribution of strength of the $\mathrm{Nb}_{3} \mathrm{Al}$ fiber with that of $\mathrm{Nb}_{3} \mathrm{Al} / \mathrm{Cu}$ composite for a gauge length of $50 \mathrm{~mm} / 12 /$. 


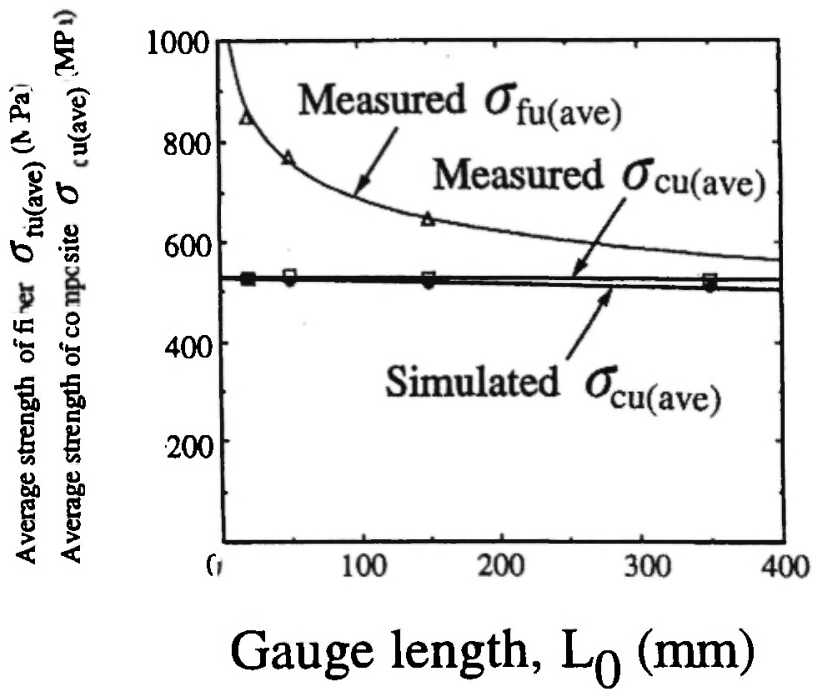

Fig. 13: Measured average strengths of the $\mathrm{Nb}_{3} \mathrm{Al}$ fibers $\sigma_{\text {fixavo) }}$ and $\mathrm{Nb}_{3} \mathrm{Al} / \mathrm{Cu}$ composite $\sigma_{\text {eu(avo), }}$ plotted against gauge length $\mathrm{L}_{0}$, together with the simulation result for composite strength $/ 12 \%$.

the weakest fiber determines the scatter of composite strength. However, as the strength of each individual fiber is not very different, the scatter of composite strength is not large. On the other hand, when the fiber strength has large scatter, a cumulative fracture mode controls the strength of the composite. In this mode, the number of the fiber breakages increases with applied stress. The accumulated breakages work together to cause overall fracture of the composite. As the number, locations and progress of accumulation of the fiber breakages differ from sample to sample, the strength of the composite also differs from sample to sample, resulting in the scatter of composite strength.

The present results, both measured and simulated, for $\mathrm{Nb}_{3} \mathrm{Al} / \mathrm{Cu}$ composite with large scatter of fiber strength indicate that the stress level needed to cause overall fracture of the composite by joint action of the fiber breakages is not very different between samples, and is affected only slightly by the length. Thus, in spite of a large strength scatter and a strong strength length-dependence of stress-carrying fibers, the strength of metal matrix composites has essentially small scatter and also very weak dependence on length, unless strength-determining defects are not introduced duning the fabrication of composites. This factor is very useful in the practical application of metal matrix composites as industrial materials from the point of view of reliability.

\subsubsection{Influence of test-temperature on the strength of composites}

Fiber-reinforced metal matrix composites are used for various high-temperature applications in aerospace and automobiles. However, it is known that the strength of most continuous fiber-reinforced metal matrix composites decreases with increasing temperature. Such a temperature dependence could be described by the simulation and the mechanism identified, as follows:

When the temperature is raised, the matrix is softened (yield stress and elastic moduli of the matrix decrease) while other factors such as strength distribution and elastic moduli of fiber and interfacial bonding strength remain in most cases. As a result, the critical length $l_{c}$ of broken fibers (see Fig. 2(b)) increases and the stress concentration factor $\mathrm{K}$ in the neighboring fibers (see Fig. 2(c)) decreases with increasing temperature $/ 10 \%$. This indicates that the softening of matrix at high temperatures can act to raise the strength of the composite from the point of decrease in stress concentration $\mathrm{K}$, but on the other hand, it can act to reduce the strength from the point of increase in critical length $l_{c}$, which reduces the stress-carrying capacity of broken fibers for a long distance. Thus, the strength of the composite is determined by competition of these opposing factors.

The experimental result, showing that the composite strength decreases with increasing temperature (Fig. 14(a) /10/), suggests that the influence of an increase in $\mathrm{l}_{c}$ predominates over that of a decrease in $\mathrm{K}$. In order to demonstrate this suggested mechanism, only the temperature-dependence of $\mathrm{K}$ and $\mathrm{l}_{\mathrm{c}}$ on temperature were incorporated, without changing other factors, and the Monte Carlo simulation was carried out, for which the strength distribution of the extracted fibers was estimated in advance in a similar manner to $\mathrm{Nb}_{3} \mathrm{Al}$ fibers shown in 3.2.2. The results of simulation carried out 5 times for each temperature are presented in Fig. 14(b). They agree well with the measured results. This, in turn, indicates that the mechanism for the reduction in composite strength at high temperature could be 


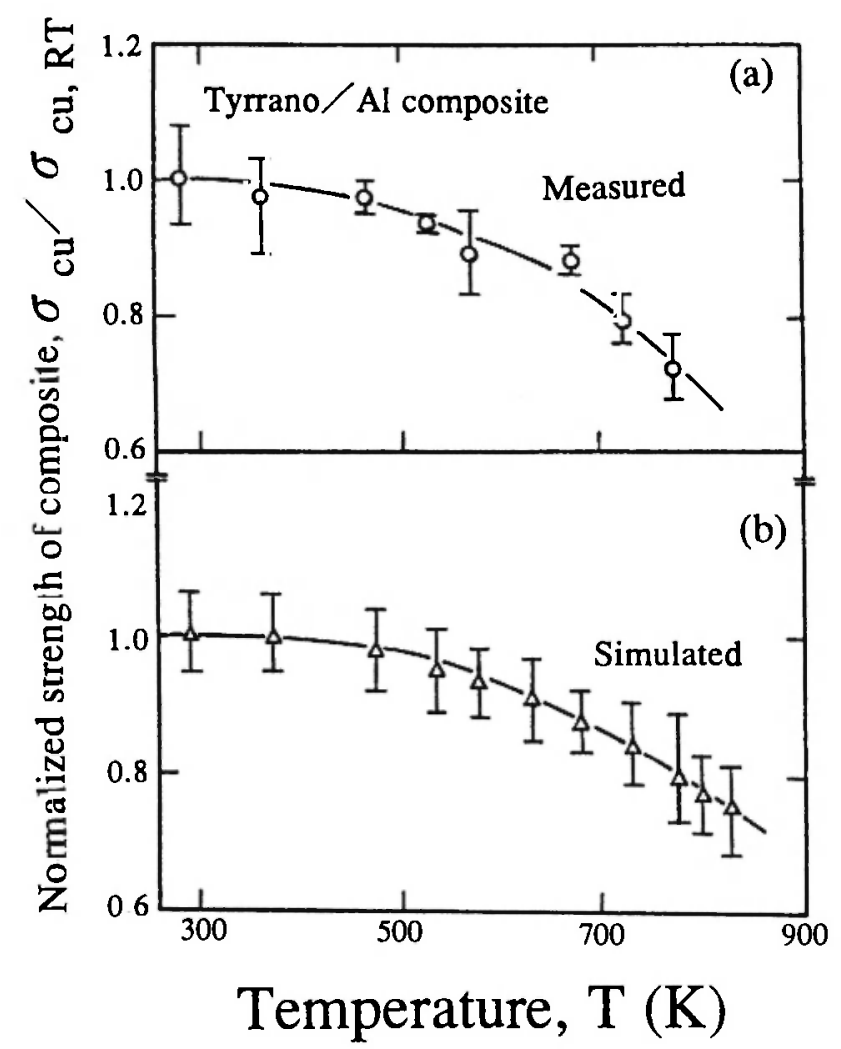

Fig. 14: (a) Measured $/ 10 /$ and (b) simulated temperature-dependence of strength of Si-TiC-O (Tyrrano)/Al composite.

attributed to the predominance of the effect of the matrix-softening-induced increase in critical length over that of the decrease in stress concentration.

The situation stated above is shown schematically in Fig. 15 (a) and (b), where the closed circles show the broken fiber-elements, the open ones show the unbroken and stress carrying elements existing beyond half the critical length from the broken elements, and the longitudinal solid lines above and below the broken elements cover the "ineffective" elements which are not broken but unable to carry applied stress sufficiently, existing within half the critical length from the broken elements. Due to the increase in critical length at high temperature, the number of such ineffective elements increases, resulting in low efficiency of the reinforcement. This mechanism is reflected in the fact that the fracture surface at low and high temperatures shows short and long pull-out of fibers, respectively (Fig. $15\left(\mathrm{a}^{\prime}\right)$ and $\left(\mathrm{b}^{\prime}\right)$ ).

\subsubsection{Influence of fabrication condition on the strength of composite}

When a mono-layer $\mathrm{B} / \mathrm{Al}$ composite is prepared by the hot-press technique under a fixed pressure, the interfacial condition varies with increasing pressing time $t$. When $t$ is short, interfacial reaction is slight and interfacial bonding strength is low. With increasing $t$, the interfacial bonding strength becomes high and interfacial reaction proceeds $/ 21$. Figure 16 shows three typical cases: (a) interfacial bonding is weak (short $t$ ), (b) interfacial bonding is strong and the thickness of the reaction layer $\mathrm{AlB}_{2}$ is small (intermediate $\mathrm{t}$ ), and (c) interfacial bonding is strong but excess reaction has occurred (long t) $/ 20,21 /$. More than 5 samples were tested for each condition.

The experimental results presented in Fig. 16 have been explained qualitatively as follows. The average fiber stress $\sigma_{\mathrm{fu}}$ in the composite at ultimate loading increases with increasing $t$ due to the increase in interfacial bonding strength, which raises the efficiency of the stress transfer from matrix to fibers, but it then decreases due to the degradation mechanism of premature cracking of $\mathrm{AlB}_{2}$ 122,23/. The fracture surface for case (a) shows the long pull-out of fibers, suggesting low efficiency of the stress-transfer. With increasing $t$, the pull-out length becomes short, indicating improvement of the efficiency. For long $t$, the fracture of composite occurs just perpendicular to the tensile axis. These qualitative explanations can be converted to the quantitative ones by the simulation.

For the simulation, the interfacial shear strength and frictional shear stress at interface after debonding for (a) were estimated to be 10 and $2 \mathrm{MPa}$, respectively, from the pull-out test. The former and the latter values for (b) were $20 \mathrm{MPa}$ (the same as the shear yield stress of the present matrix) and $2 \mathrm{MPa}$, respectively. For case (c), as no interfacial debonding was observed in the fracture surface, the interface was treated in the simulation to be strong enough to prevent debonding. For all cases, the strength distributions of extracted fibers were measured and the distribution parameters thus obtained were input in the simulation. In case (c), a circumferential crack is formed on the fiber surface due to premature fracture of $\mathrm{AlB}_{2}$. The crack formed propagates into fiber, resulting in fiber breakage $122,23 /$. This mechanism, whose procedure is shown in 


\section{Low temperature}

\begin{abstract}
0000000000000000000000000 0000000000000000000000000 0000000000000000000000000 0000000000000000000000000 1000000000000000000000000 0000000000000000000000000 0000000000000000000000000 000000000000000000000000 0000000000000000000000000 $000] 100000000000000000000$ 000000000000000000000000 $000][00000000000000000000$ 0000000000000000000000000 0000000000000000000000000 00000000000000,0000000000 0000000000000000000000000 0000000000000000000000000 0000000000000000000000000 0000000000000000000000000 0000000000000000000000000 0000000000000000000000000 000000000000000000000000 0000000000000000000000000 0000000000000000000000000 0000000000000000000000000
\end{abstract}

$$
\text { (a) }
$$

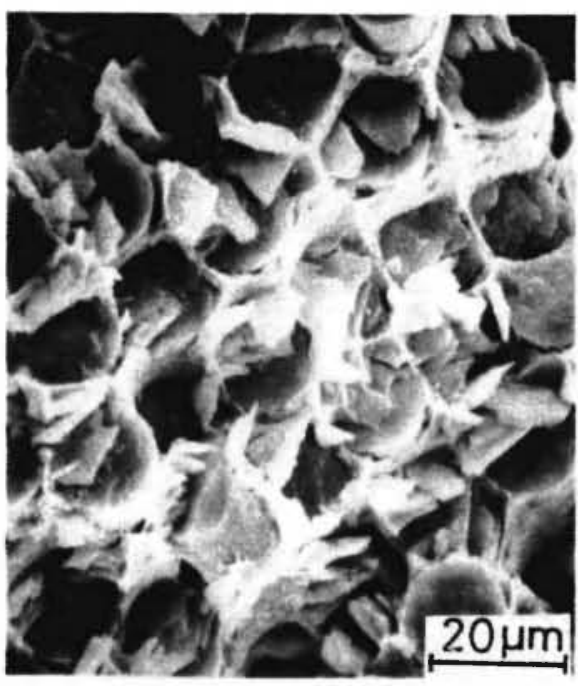

(a')

\section{$\rightarrow$ High temperature}

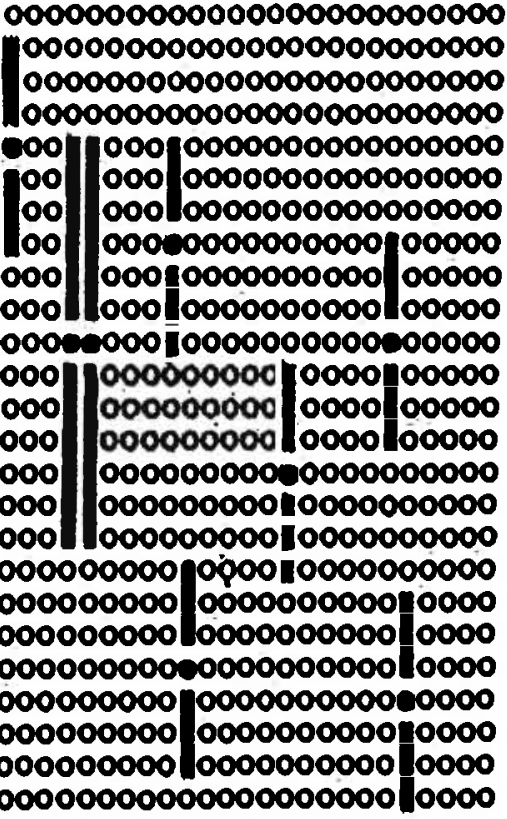

(b)

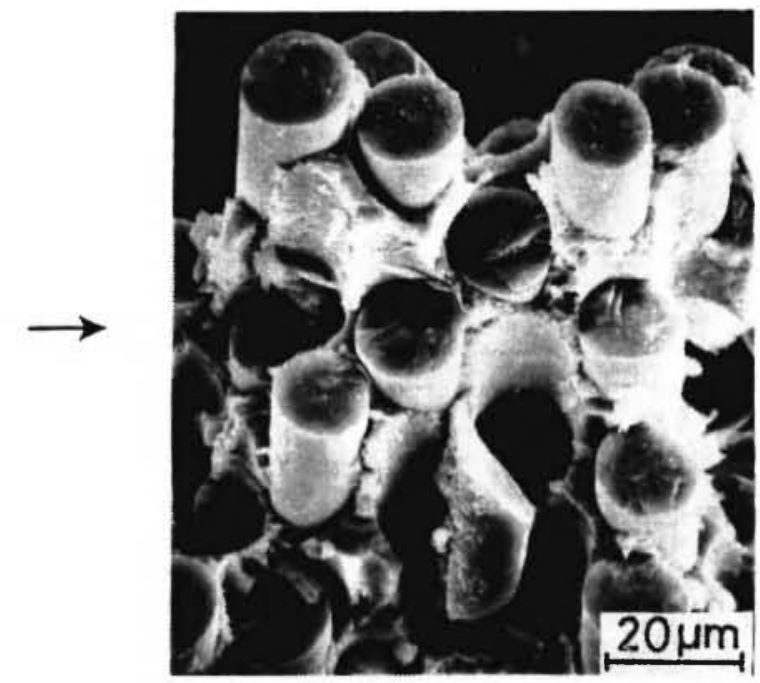

$\left(\mathrm{b}^{\prime}\right)$

Fig. 15: Schematic representation of the configuration of fiber-elements in composite at (a) low and (b) high temperatures, together with the fracture surfaces. The closed circles show the broken elements and the open ones the unbroken and stress-carrying ones. The solid lines above and below the broken elements show the ineffective elements which are not broken but unable to carry applied stress sufficiently since they exist within half critical length from the broken elements. 


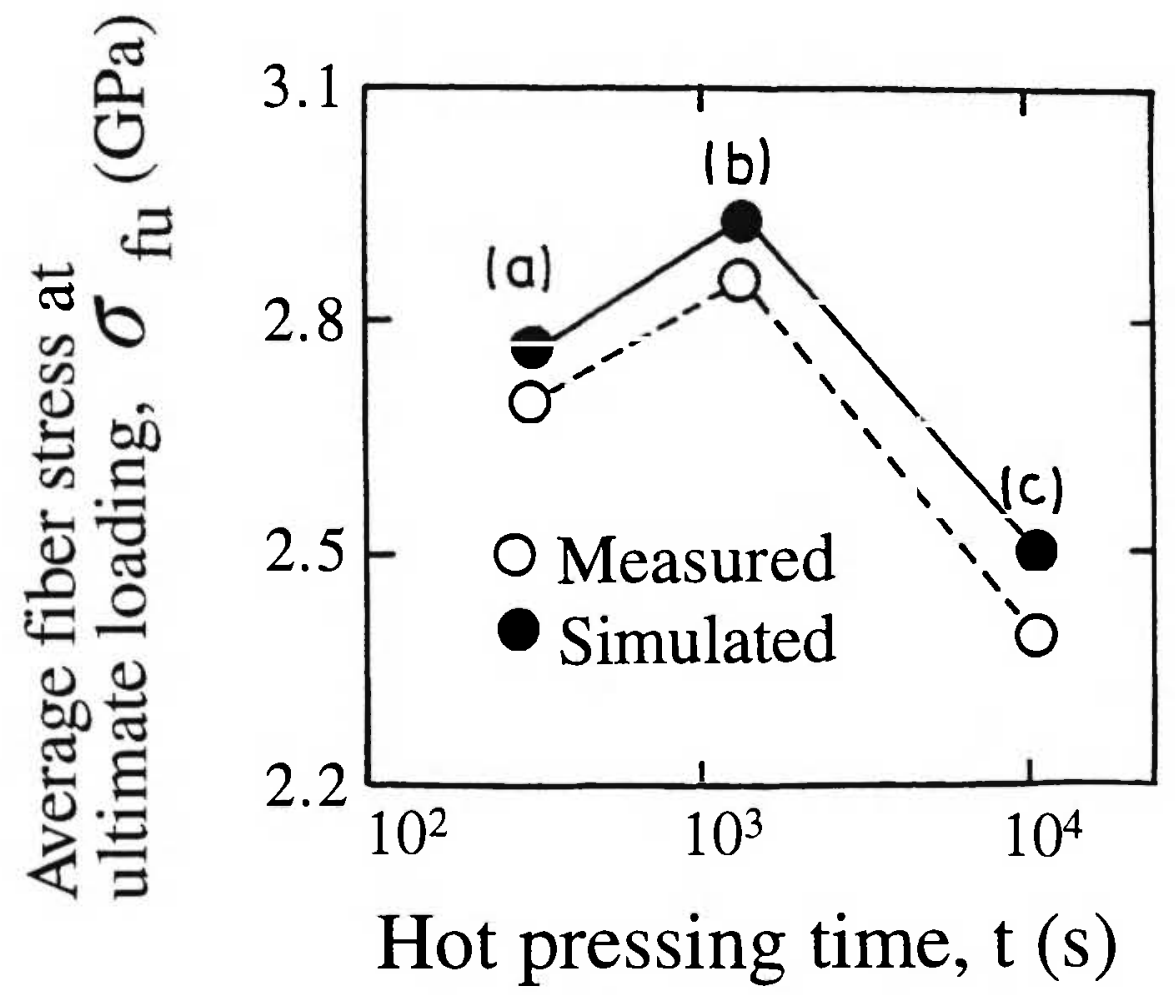

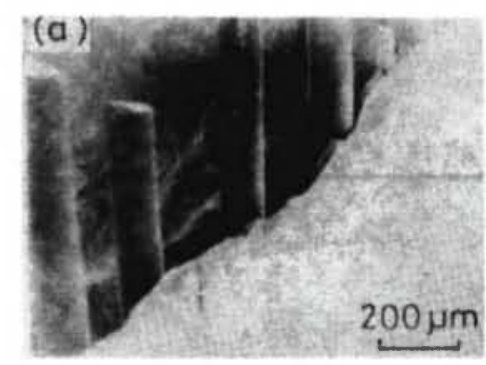

0000000000900000000000000 0000000000 C 5000000000000 000000000000000000000000 000000000 o 1 p 0000000000 $0000000000 \mathrm{~g}$ p000 00000000000 p pas poo p pa p.

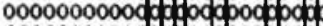

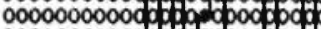
000 s000000 of doc poch pabp

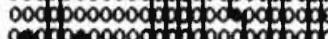
anppoocos: pocpo po p op: A:

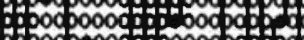
500 poc: 50000 oc: $: 50$ a (a)

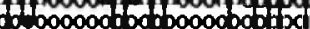

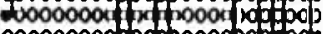
00000000 C pap 000 ac 0000000 bo 10000 000000000 od $000000+00000$

(a)

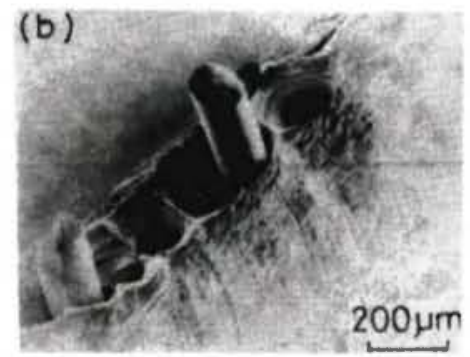

0000000000000000000000000 000000000000000000000000 $00000000000000000000000 \mathrm{ch}$ $00000000000000000000000 \mathrm{cp}$ $0000000000000000000000 \mathrm{Cl}$ 000000000000010000000000 Oa9 $0000009001000000000 \mathrm{CD}$ 0000000000000000000000000 00000000000000000000000 0000000000000000000000000 00000000000000000000000

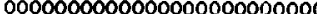
00000000000000000000 000000000000000000000000 $0000000000000 \div 00000000000$ 0000000000000000000000000 0000000000000000000000000 0000000000000000000000000 00000000000000000000000 0000000000000000000000000 0000000000000000000000000 0000000000000000000000000 00000000000000000000000 000000000000000000000000

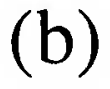

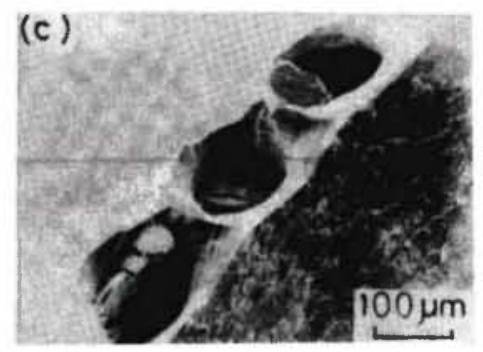

0000000000000000000000000 11000000000000000000000000 0000000000000000000000000 000000000000000000000000 ? 00000000000000000 0000000000000000000000000 0000000000000000000000000 0000000001000000000000000 0000000000000000000000000 0000000000000000000000000 00000000,100000000000000000

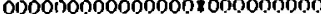
0000000000000000000000000 $000001) 0001) 002000000000$ 000000000000000000000000 0000000000000000000000000 0000000000000000000010000 00000000000100000000000000 0000000000000000000000001 0000000000010000000000000 0000000000000000000000000 onnono00000000000000000no anat

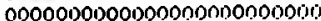
oonoononoonougoonotononopan

Fig. 16: Measured and simulated variation of fracture surface and average stress of fiber at ultimate stress of monolayer $\mathrm{B} / \mathrm{Al}$ composite as a function of hot-pressing time $\mathrm{t} / 20 \%$. 
Ref /24/, was incorporated in the simulation.

In Fig. 16, simulated average fiber stress at ultimate loading from a simulation for each condition and simulated typical fracture morphology of composite (carried out 10 times) are superimposed. The experimentally observed features agree well with the simulation.

The reason why the composite with an excess reaction layer shows catastrophic fracture can be explained as shown in Fig. 17. When a fiber is broken due to the extension of the crack formed by the premature fracture of the $\mathrm{AlB}_{2}$ layer, high stress concentration is exerted on the neighboring fibers, which causes fracture of the reaction layer on the neighboring fibers, which in turn are also broken. As the number of broken fibers increases, higher stress concentration is exerted on the next neighboring fibers, which causes fracture of the reaction layers and fibers even under the same stress level. In this way chain reactions of breakages of the fiber and the reaction layer occur one after another, resulting in catastrophic fracture.

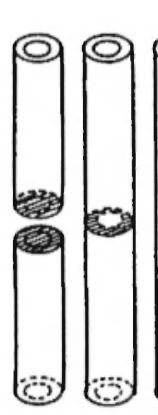

(a)

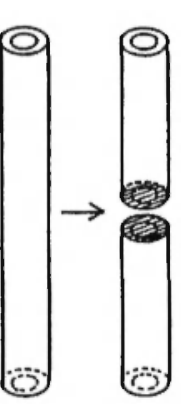

(b)
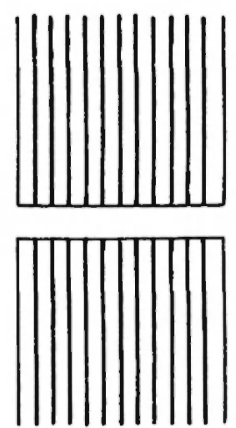

(c)
Fig. 17: Schematic representation of fracture process of composites in which a brittle reaction layer is formed on fiber surfaces due to the interfacial reaction between fiber and matrix.

\section{CONCLUSIONS}

Multiple fracture of fiber in single fiber-metal matrix composites $\left(\mathrm{YBa}_{2} \mathrm{Cu}_{3} \mathrm{O}_{\mathrm{x}} / \mathrm{Ag}, \mathrm{Bi}_{2} \mathrm{Si}_{2} \mathrm{Ca}_{2} \mathrm{Cu}_{3} \mathrm{O}_{\mathrm{y}} / \mathrm{Ag}\right.$ and $\mathrm{W} / \mathrm{Cu}$ ), and tensile behavior of unidirectional multifiber ones (B/Al, Si-Ti-C-O (Tyrrano fiber)/Al, $\mathrm{Nb}_{3} \mathrm{Al} / \mathrm{Cu}$ ) were simulated by the Monte Carlo simulation method. The main results are summarized as follows:

1) The multiple fracture process of the originally continuous $\mathrm{W}$. fiber in single fiber $\mathrm{W} / \mathrm{Cu}$ composite could be simulated well by the present method. The dependence of the critical length on the volume fraction of fiber in the case of single fiber composites was demonstrated.

2) From the comparison of the experimentally observed multiple fracture process of high $T_{0}$ superconducting $\mathrm{YBa}_{2} \mathrm{Cu}_{3} \mathrm{O}_{x}$ and $\mathrm{Bi}_{2} \mathrm{Sr}_{2} \mathrm{Ca}_{2} \mathrm{Cu}_{3} \mathrm{O}_{y}$ fibers in silver matrix with simulated ones, the shear strengths of the interface were estimated to be nearly 30 and $40 \mathrm{MPa}$, respectively.

3) The tendency that the fracture of composites occurs in cumulative and non-cumulative modes for large and small scatters of fiber strength, respectively, was simulated well for the $\mathrm{B} / \mathrm{Al}$ composite.

4) The experimentally observed tendencies for $\mathrm{Nl}_{3} \mathrm{Al}$ / $\mathrm{Cu}$, that the scatter of strength of multifilamentary composite becomes smaller than that of contained fibers and the dependence of composite strength on gauge length becomes very weak in spite of strong dependence of fiber strength on length, were well simulated.

5) The present simulation was able to describe the temperature dependence of strength of Tyrrano fiber/Al composite. The softening of matrix at high temperature leads to (a) an increase in critical length, which acts to reduce the strength of composite due to a decrease in the efficiency of stress transfer from matrix to broken fiber, and (b) a decrease in stress concentration arising from fiber breakages, which raises the strength of composites. The reduction in composite strength at high temperature could be attributed to the predominance of the former effect over the latter.

6) The influence of fabrication conditions, including variations of interfacial bonding strength and formation of brittle reaction layer on strength and fracture morphology of $\mathrm{B} / \mathrm{Al}$ composite, could be accomplished in the computer.

\section{ACKNOWLEDGMENTS}

The authors wish to express their gratitude to the 
Ministry of Education, Science and Culture of Japan for the Grant-in-Aid No. 06452320.

\section{REFERENCES}

1. A. Kelly and W.R. Tyson. In: High Strength Materials, V.F. Zackay (ed.), John Wiley \& Sons, New York, 1965; 578.

2. S. Ochiai. In: Mechanical Properties of Metallic Composites, S. Ochiai (ed.), Marcel Dekker Inc., New York, 1994; 473.

3. S. Ochiai and K. Osamura. Z. Metallkd., 77, 255 (1986).

4. S. Ochiai and K. Osamura. J. Mater. Sci., 21, 2735 (1986).

5. S. Ochiai, P.W.M. Peters, K. Schulte and K. Osamura. J. Mater. Sci., 26, 5433 (1991).

6. S. Ochiai, K. Hayashi and K. Osamura. Met. Mater. Trans., 25A, 349 (1994).

7. S. Ochiai and K. Osamura. J. Mater. Sci., 23, 886 (1988).

8. S. Ochiai, K. Osamura and K. Abe. Z. Metallkd., 76, 402 (1985).

9. S. Ochiai and K. Osamura. Met. Trans., 21A, 971 (1990).

10. S. Ochiai, K. Matsunaga, Y. Waku, T. Yamatsuta, M. Hojo and K. Osamura. Met. mater. Trans., 26A, 647 (1995).
11. W. Weibull. J. Appl. Mech., 28, 293 (1951).

12. S. Ochiai, T. Sawada, S. Nishino, M. Hojo, $\mathrm{K}$. Takahashi and Y. Yamada. Cryogenics, 36, 244 (1996).

13. E.D. Reedy, Jr. J. Mech. Phys. Solids, 28, 265 (1980).

14. S. Ochiai, K. Abe and K. Osamura. Z. Metallkd., 76, 299 (1985).

15. S. Ochiai, K. Osamura, K. Tokinori, M. Nakatani and K. Yamatsuta. Met. Trans., 22A, 2085 (1991).

16. G.W. Zender and J.W. Deaton, NASA TN-D1609, NASA, Washington, 1963.

17. E.D. Reedy, Jr. J. Comp. Mater., 18, 595 (1984).

18. W.H. Herring, J.L. Lytton and J.H. Steele, Jr. Met. Trans., 4, 807 (1973).

19. S. Ochiai and M. Hojo. Materia (Bull. Jpn. Inst. Metals), 33, 1397 (1994) [in Japanese].

20. S. Ochiai and M. Hojo. Comp. Interfaces, 5, 365 (1994).

21. S. Ochiai, K. Abe and K. Osamura. J. Japan Inst. Metals, 48, 1028 (1984) [in Japanese].

22. A.G. Metcalfe and K.M. Prewo. In: Composite Materials, Vol. 1, A.G. Metcalfe (ed.), Academic Press, New York, 1974; 399.

23. S. Ochiai, Y. Irie and K. Osamura. Z. Metallkd., 74, 44 (1983).

24. S. Ochiai and K. Osamura. Met. Trans., 18A, 673 (1987). 